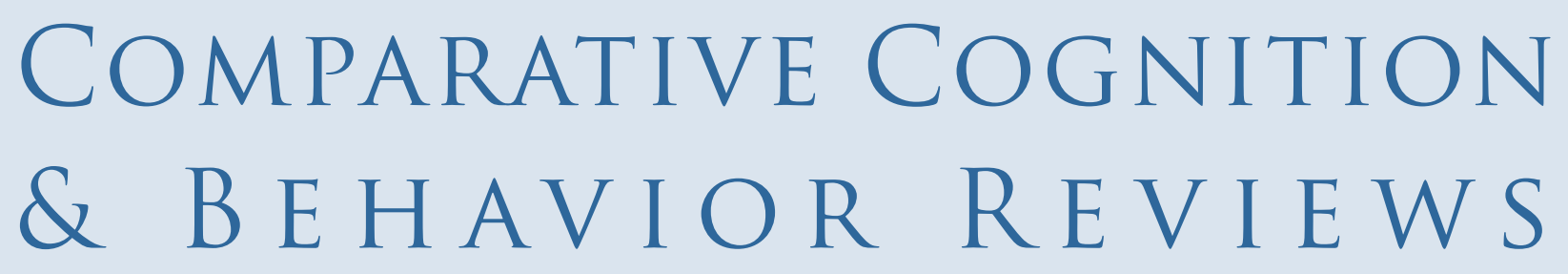

\title{
In Memory of Ronald G. Weisman
}

\author{
(SEPTEMBER 14, 1937 - JANUARY 27, 2015)
}

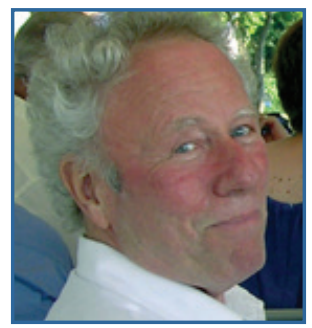

W ith his family by his side, Ron Weisman, Professor Emeritus, Departments of Psychology and Biology, Queen's University, died at home on 27 January 2015. Ron obtained his $\mathrm{Ph} . \mathrm{D}$. from Michigan State University in 1964 and was hired as Assistant Professor of Psychology at Queen's in that same year. Ron was promoted to Associate Professor in 1970, Professor in 1977, cross appointed to the Department of Biology in 1993, and finally promoted to Professor Emeritus in 2000. In sum, Ron was a professor at Queen's for over 50 years. He is well known for his numerous significant contributions to our understanding of animal learning, cognition, and behaviour. Maybe more important, but not so easily tallied with facts and numbers, are the more qualitative and impactful contributions that Ron made to the research areas in which he was so totally and passionately invested during his long and productive career but that escape the accountant's ledger. Of these less quantifiable, but absolutely important contributions, one cannot hope to produce a comprehensive report here. And Ron himself would not want such a thing. "Too many words that no one is likely to read or care about" would probably be his quip in response to such an idea. No, the manner in which Ron operated and conducted himself is best described using the words of those who have commented about Ron's influence in the days since his passing. Strong themes like "force of nature", "intellectually challenging", "passionate", "inspiring" are a constant in Ron's colleagues' narratives shared in conversations, social media, and emails. Never one to back down from a challenge, Ron reinvented his research career from the ground up when he realized an opportunity to pursue new more challenging but meaningful problems. This categorical change came when Ron was at a point in his career in which most people would be happy to simply maintain the currently successful status quo until retirement. Not Ron. Instead, and in spite of, or perhaps, because of, the fear of the unknown, Ron forged a second, even more well-known career for himself, combining research in learning, cognition, ethology, and neuroscience in a manner not often done, certainly not with the same effect. While on this new path, Ron continued to make significant contributions to the scientific literature and to the field through the founding of the Comparative Cognition Society, and their flagship online and open access journal, Comparative Cognition \& Behavior Reviews. Perhaps Ron's most enduring legacy will be of the contributions that he made to the mentorship and encouragement of young scientists. Many successful scientists owe their "academic legs" to Ron's strong and generous support and wisdom. Ron posed challenging questions and championed points of view that were sometimes controversial and always aimed at pushing back the darkness to, as Ron put it, "Explain nature". Ron always managed to be engaging, encouraging, and able to coax the absolute best out of everyone who was willing to meet his enthusiasm and level of commitment to science. Ron's enthusiasm, wit, candor, compassion, and his huge smile will be sorely missed by all who had the pleasure of knowing him. What a guy.

Christopher B. Sturdy \& Marcia L. Spetch University of Alberta 